\title{
Enhancement of Shikalkin Production in Arnebia euchroma Callus by a Fungal Elicitor, Rhizoctonia solani
}

\author{
Payam Arghavani, Kamalhdin Haghbeen *, Amir Mousavi
}

Department of Plant Bioproducts, National Institute of Genetic Engineering and Biotechnology, Tehran, Iran ${ }^{*}$ Corresponding author: Kamalhdin Haghbeen, Department of Plant Bioproducts, National Institute of Genetic Engineering and Biotechnology, Tehran,
Iran. Tel: +98-44787372, Fax: +98-44787399, E-mail: kamahl@nigeb.ac.ir

Received: February 15, 2015; Revised: May 22, 2015; Accepted: August 02, 2015

Background: There is a growing demand for mass production of shikalkin (a natural pigment consisted of shikonin and alkannin) due to its increasing applications in cosmetics, pharmaceutical and nutrition industries. The root of Iranian Arnebia euchroma produces shikalkin. The promising capability of this plant for shikalkin production has already been demonstrated in cell culture studies.

Objectives: Elicitation effect of Rhizoctonia solani (R. solani) in comparison with the effects of $\mathrm{Cu}^{2+}$, methyl jasmonate (MJ), and salicylic acid (SA) on the shikalkin production was investigated in A. euchroma callus.

Materials and Methods: The calli from different origins (leaf, collar and root) were proliferated on a modified LinsmaierSkoog (mLS) medium and were subsequently transferred onto the pigment production medium containing various amounts of the desirable elicitor. Observations were quantified and the pigment production was precisely measured spectrophotometrically.

Results: Pigment biosynthesis was induced on White medium containing IAA $(1 \mu \mathrm{M})$ and kinetin $(10 \mu \mathrm{M})$ in dark at $25^{\circ} \mathrm{C}$. Use of $R$. solani increased the pigment production by 7 fold greater than normal White medium. $\mathrm{Cu}^{2+}$ only doubled the shikalkin production. MJ and SA showed enhancing effects comparable to that of $\mathrm{Cu}^{2+}$.

Discussions: It is assumed that upon binding of the polysaccharides of the fungal cells to the plant cell surface, a cascade of signaling is initiated that led to expression of genes involving in the biosynthesis of shikalkin.

Keywords: Arnebia euchroma; Elicitor; Rhizoctonia solani; Shikalkin

\section{Background}

Shikalkin is a mixture of shikonin (S-enantiomer) and alkannin (R-enantiomer), Figure 1. They are usually biosynthesized along with their esters in the plant cells of some members of Boraginaceae (1). In addition to A. euchroma, shikalkin is found in some other genus of Boraginaceae such as Lithospermum, Alkanna and Onosma (2). Shikonin was the first plant secondary metabolite, which was produced in commercial scale by the cell culture of Lithospermum erythrorhizon (1). The demand for the large scale production of shikalkin is increasing due to its attractive color and pharmaceutical properties $(3,4)$. The number of the research papers on the medicinal properties of shikalkin is growing and no toxicity has been reported for the use of the pigment (5-8).

Although a great deal of information about the biosynthesis and mass production of shikalkin comes from L. erythrorhizon cell culture studies, it has been shown that the A. euchroma cells are similarly capable of shikalkin production (9). $p$-Hydroxybenzoic acid (PHB), derived from the phenylpropanoid pathway, and geranyl-pyrophosphate (GPP), from the mevalonic acid pathway, join together under the effect of PHBgeranyl transferase to initiate shikalkin biosynthesis (Figure 1). Phenylalanine lyase (PAL) and 3-hydroxy3-methyl-glutaryl-CoA reductase (HMGR) play key roles in the shikalkin pathway (10). Light, ammonium and 2,4-dichlorophenoxyacetic acid (2,4-D) inhibit the shikalkin formation while 3 -indoleacetic acid (IAA) and copper ion $\left(\mathrm{Cu}^{2+}\right)$ induce its biosynthesis (11).

In vitro production of shikalkin is accomplished through a two-stage plan including proliferation and production steps. In the first step, the plant cells are proliferated on a growth medium such as LinsmaierSkoog (LS) containing 2,4-D and $N$-(2-furanylmethyl)-1H-purin-6-amine (kinetin). In the second step, the cells are transferred to a production medium 


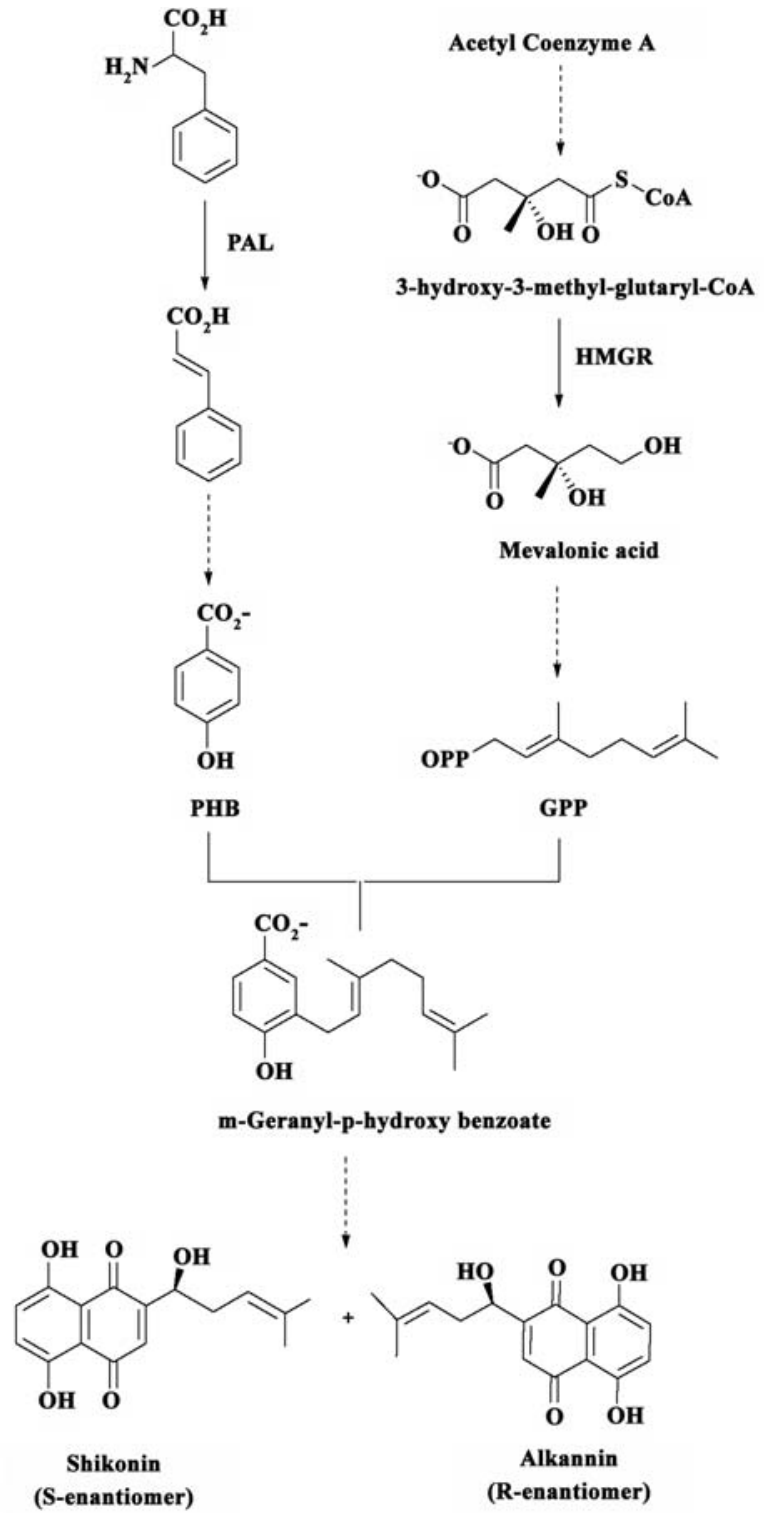

Figure 1. Biosynthetic pathway of shikalkin

such as White medium containing IAA and kinetin. The whole process is carried out in the darkness at $25^{\circ} \mathrm{C}(12-15)$.

Elicitors are compounds that in low concentrations enhance secondary metabolite production (16). The advantage of using elicitors for shikalkin production has been demonstrated. For instance, the effect of oligogalactoronides, methyl jasmonate (MJ) and stresses caused by gama radiation and ultrasonic waves on $L$. erythrorhizon culture have been studied (17-20). The positive effects of fungal elicitors such as Aspergillus niger and Rhizopus oryzae and some micro-elements such as $\mathrm{Cu}^{2+}$ in the cell cultures of $A$. euchroma have also been demonstrated $(12,21)$. In pursuit of these studies, the effects of MJ, salicylic acid (SA) and the extract of $R$. solani (a plant fungal pathogen) on the pigment production were examined in callus of Iranian A. euchroma.

\section{Materials and Methods}

\subsection{Chemical and Plant Materials}

Kinetin, 2,4-dichlorophenoxyacetic acid (2,4-D), 3indoleacetic acid (IAA), MJ and SA were purchased from Sigma ${ }^{\mathrm{TM}}$ Chemical and Biochemical Company (St. Louis, MO, USA). All other chemicals were taken from the authentic samples. Solid Murashige-Skoog (MS), LS and White media were prepared according to the literature using 8 g.L-1 agar (12). Modified LS (mLS) was made according to our previous work (9). A. euchroma specimens were collected and determined as described earlier (9). Seed germination and callus induction were successfully carried out according to the reported method (14). The resulting calli from leaf, collar and root explants, obtained from young plantlets, were propagated first on MS medium supplemented with sucrose $\left(50\right.$ g. $\left.\mathrm{L}^{-1}\right), 2,4-\mathrm{D}\left(10^{-6} \mathrm{M}\right)$, and kinetin $\left(10^{-5} \mathrm{M}\right)$ during three successive subcultures at $25^{\circ} \mathrm{C}$ in darkness. The propagation medium was then changed from MS to mLS for another three successive subcultures. Subcultures were carried out every three weeks. To calculate the biomass, the weights of the calli were recorded before and after drying at $37^{\circ} \mathrm{C}$ for $48 \mathrm{~h}$.

\subsection{Preparation of Elicitors}

The stock solutions of MJ and SA were made by dissolving the desirable amount of the elicitor in $96 \%$ $(\mathrm{v} / \mathrm{v})$ ethanol $(\mathrm{EtOH})$. The resulting solutions were stored at $4^{\circ} \mathrm{C}$. Fungus pathogen, $R$. solani was procured from University of Tehran Microbes Collection (UTMC). R. solani was propagated in YES medium [50 mL of sucrose (150 g.L $\left.\mathrm{L}^{-1}\right)$, yeast extract $\left(20 \mathrm{~g} . \mathrm{L}^{-1}\right)$, $\mathrm{MgSO}_{4} .7 \mathrm{H}_{2} \mathrm{O}\left(0.5\right.$ g.L $\left.\mathrm{L}^{-1}\right), \mathrm{CuSO}_{4} .5 \mathrm{H}_{2} \mathrm{O}\left(0.005\right.$ g.L $\left.{ }^{-1}\right)$ and $\mathrm{ZnSO}_{4} \cdot 7 \mathrm{H}_{2} \mathrm{O}\left(0.01\right.$ g. $\left.\left.\mathrm{L}^{-1}\right)\right]$ (15) in a flask $(250$ $\mathrm{mL})$. The flask was shaken $(100 \mathrm{rpm})$ in dark at $25^{\circ} \mathrm{C}$ for 5 days. The biomass was filtered, autoclaved and dried through two successive stages $\left(70^{\circ} \mathrm{C}\right.$ for $48 \mathrm{~h}$ and $37^{\circ} \mathrm{C}$ for 4 days). The dried biomass was powdered and stored at $4^{\circ} \mathrm{C}$.

\subsection{Shikalkin Production by the Callus}

The proliferated plant callus was transferred on White medium containing IAA $(1 \mu \mathrm{M})$, kinetin $(10 \mu \mathrm{M})$ and $8 \%(\mathrm{w} / \mathrm{v})$ agar to initiate pigment production. 
Shikalkin formation was investigated on White media containing various amounts $(0,0.25,0.5,1$ and $2 \mathrm{mM})$ of MJ and SA. To study the effect of the fungal elicitor, White media containing $\left(10,20,40\right.$ and $\left.80 \mathrm{mg} . \mathrm{L}^{-1}\right)$ of the $R$. solani powder were used in the experiments. To examine the effect of the solvent (ethanol), the pigment production on White media containing $(0,4.25,8.5,17$ and $34 \mathrm{mM}$ ) of EtOH was also examined. White medium and a White medium containing copper ion $(0.3$ mg. $\mathrm{L}^{-1}$ ) were considered as the control and positive control media, respectively.

\subsection{Pigment Extraction and Measurements}

The callus sample was taken from the solid medium, was removed from cells and dried at $37^{\circ} \mathrm{C}$ for 48 $\mathrm{h}$. The callus was powdered and subjected to extraction by radical-free tetrahydrofuran (THF) (11). Extraction was carried out at room temperature by stirring the powder in THF for $10 \mathrm{~min}$. Concentration of the pigment in THF was determined spectrophotometrically by reading the absorbance at $520 \mathrm{~nm}$ (11). A calibration plot, obtained for the shikalkin pigment extracted from the natural root of Iranian A. euchroma, was used in calculations. Spectrophotometric measurements were carried out using an Analytik, Specord 210 (Jenna, Germany) spectrophotometer. Results for all the culture studies and the pigment measurements were based on an average of, at least, triplicate measurements.

\section{Results}

\subsection{Callus Induction and Biomass Development}

A. euchroma seeds (23\%) germinated on hormonefree MS medium. The first and the last seeds germinat-

A

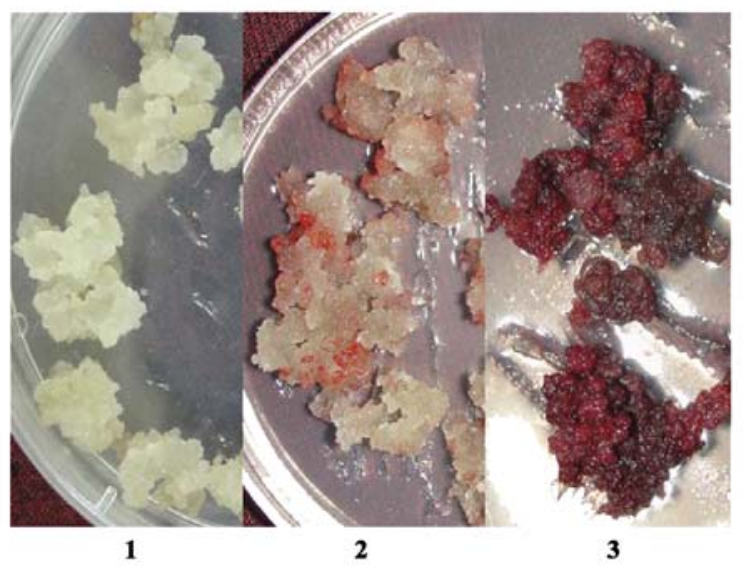

ed on the $4^{\text {th }}$ and $57^{\text {th }}$ day of the experiment, respectively. Callus induction was successfully occurred for all collar, leaf and root explants on MS medium containing kinetin $(10 \mu \mathrm{M})$ and $2,4-\mathrm{D}(1 \mu \mathrm{M})$. The first callus induction was observed on the $7^{\text {th }}$ day and the last one on the day of 15. Biomass development accomplished through three subcultures. The callus from the collar origin showed the highest proliferation rate (Table 1). In parallel to the previous observations (9), the best results were belonged to the calli propagated on mLS medium containing kinetin $(10 \mu \mathrm{M})$ and 2,4-D $(1 \mu \mathrm{M})$.

\subsection{Shikalkin Production}

After transferring the propagated calli onto the designed production media, the observations and results were analyzed both qualitatively and quantitatively. White was used as the basal medium throughout these experiments with the hormonal treatment of IAA $(1 \mu \mathrm{M})$ and kinetin $(10 \mu \mathrm{M})$.

\subsubsection{Qualitative Results}

The appearance of the red color in the callus was considered as a positive response (Figure 2A). Based

Table 1. The growth rate (in percent) of A. euchroma calli from different origins in 2 weeks

\begin{tabular}{lccc}
\hline & \multicolumn{3}{c}{ Media } \\
\cline { 2 - 4 } & MS & LS & mLS \\
\hline Callus from leaf & 160 & 320 & 230 \\
Callus from collar & 290 & 230 & 330 \\
Callus from root & 280 & 140 & 160 \\
\hline
\end{tabular}

\section{B}

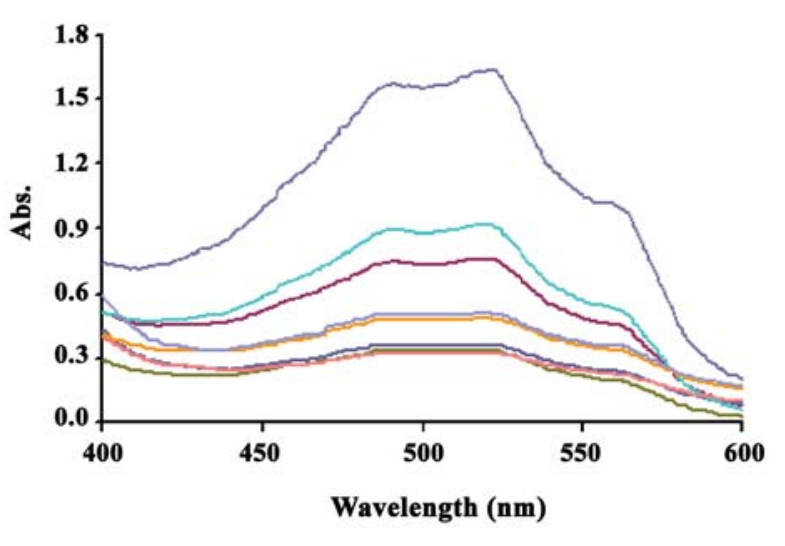

Figure 2. A: Non-pigmented (1) pigmented (2 and 3) A. euchroma calli. B: Visible spectra of some tetrahydrofuran (THF) extracts of the pigmented calli 
on this assumption, the number of petri dishes with positive responses was counted and used for qualitative analysis. The THF extract of the pigmented callus produced the characteristic visible spectrum of shikalkin (Figure 2B) (9).

\subsubsection{The Effect of Callus Origin and the Frequency of Subcultures on Shikalkin Production}

Regardless of type and concentration of the added elicitor or $\mathrm{EtOH}$, the number of Petri dishes with positive responses was counted at the end of each subculture and analyzed based on the origins of the calli (Figure 3). This analysis indicated that the calli originated from the leaf explants were able to produce about $50 \%$ positive responses at the end of the first subculture. Only $2 \%$ of the non-pigmented calli could produce shikalkin in the second subculture and there was no more positive response by the end of the third subculture. A similar result was obtained for the calli from the root origin. They produced $40 \%, 20 \%$, and $0 \%$ positive responses at successive rounds of subcultures. In contrast, the calli obtained from the collar explants were able to produce shikalkin even in the third subculture. They showed positive responses of $48 \%, 12 \%$, and $23 \%(83 \%$ altogether) at the end of each subculture (Figure 3).

\subsubsection{The Effects of Elicitors on Shikalkin Production}

Similar analysis to what was introduced in the previous section was repeated, but this time with regard to the type and concentrations of the elicitors and EtOH. These analyses were summarized in Figures 4 and 5 . EtOH had a decreasing effect on the advent of the positive answers (Figure 4). The highest number of posi-

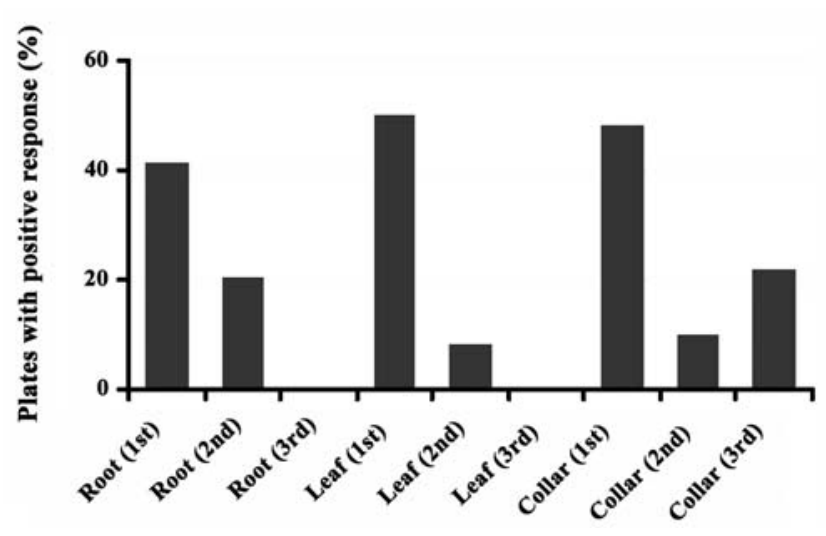

Figure 3. The positive responses of calli from different origins (root, leaf, and collar) after three (1st, 2nd, and 3rd) successive subcultures on White medium

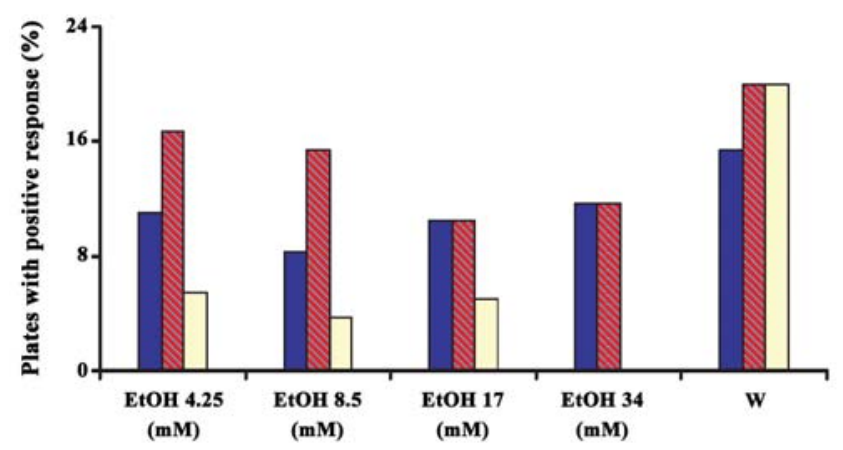

Figure 4. Effect of EtOH on shikalkin production on White (W) medium and White media containing different amounts of EtOH. Columns with dark color, diagonal lines and light color show the results of root, leaf and collar-originated calli, respectively. See the Experimental section for details

tive responses was obtained from the collar callus when it was subcultured on White medium in the presence of the fungal elicitor (40 mg. $\left.\mathrm{L}^{-1}\right)$. The second and the third rank or pigment production were also belonged to the collar in the presence of MJ $(1 \mathrm{mM})$ and SA $(0.5 \mathrm{mM})$, respectively (Figure 5).

Experiments were repeated with the collar-calli in the presence of various elicitors under the conditions, which had produced the largest amounts of shikalkin. Similar calli were simultaneously subcultured on normal White (control) and White medium containing 0.3 $\mathrm{mg} \cdot \mathrm{L}^{-1}$ of $\mathrm{Cu}^{2+}$ (positive control) (Figure 6).

\subsubsection{Quantitative Results}

Quantitative analysis of the results was accomplished by measuring the amount of the extracted pigment per gram of the dried biomass. Figure 7 illustrates the analysis of the shikalkin production data

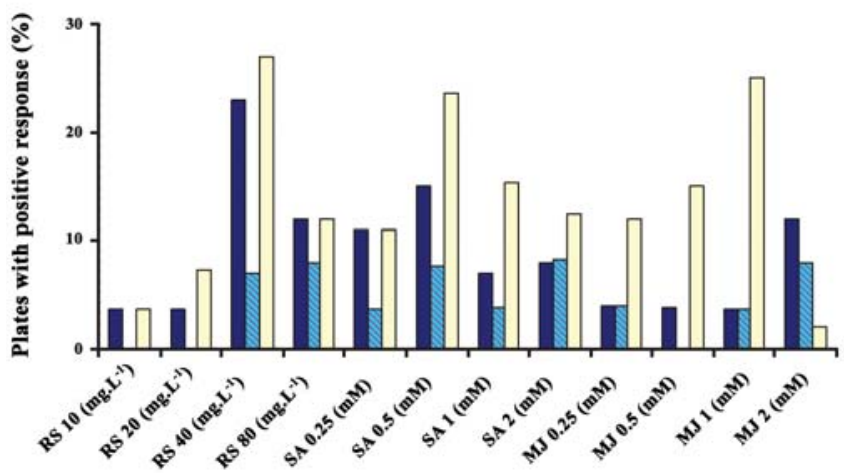

Figure 5. Effect of the examined elicitors on shikalkin production on White media containing different amounts of the elicitors. Columns with dark color, diagonal lines and light color show the results of root, leaf and collar-originated calli, respectively. RS stands for $R$. solani 


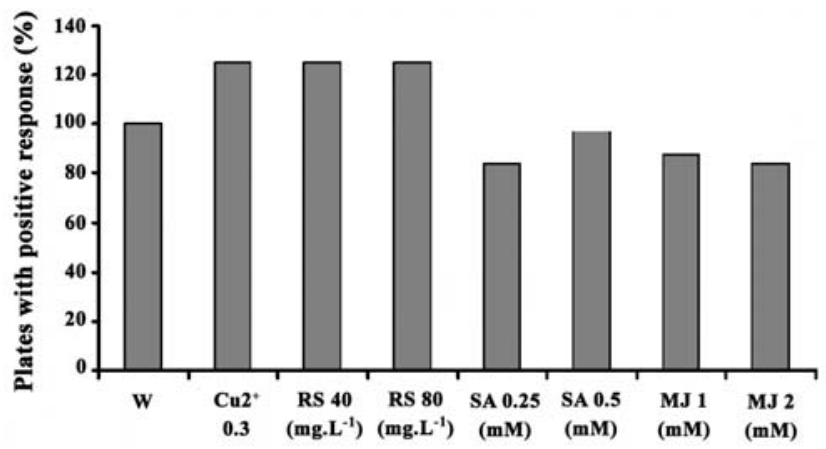

Figure 6. The number of positive responses (in percent) observed for the collar originated calli on White medium (W) and White media containing the effective concentrations of the examined elicitors. RS stands for $R$. solani

obtained from the subculture of A. euchroma callus with the collar origin under the conditions that had produced the highest responses for each elicitor.

\section{Discussion}

Callus induction in all explants of Iranian $A$. euchroma in a short period (7-15 days) revealed the potential of this species for in vitro cell culture. Root and leaf callus induction of Himalayan A. euchroma needed 16 and 20 days, respectively (23).

The number of positive responses (petri containing a callus with red pigment) reveals the biosynthetic potential of the cells with different origins under the applied conditions. Here and in respect to shikalkin production, two remarkable points need to be mentioned. First, the calli from different origins showed different biosynthetic capabilities. Among the examined calli, only the collar-originated callus was able to produce shikalkin over three successive subcultures. Second, the collar originated-callus had also the highest propagation rate. Similar observations have been reported by others (24-25). In view of the results of their research on taxol production in the Taxus suspension cultures, Kim et al. (2004) concluded that cells with high division rate and biomass development at the proliferation stage under the effect of elicitors could produce higher secondary metabolites at the production stage (24). However, it is not a general rule. For instance, in cell suspension cultures of Ginkgo biloba, MJ treatments increased the amounts of bilobalide, ginkgolide $\mathrm{A}$, and ginkgolide $\mathrm{B}$, concomitant with a slight decrease in the cell growth (25).

As mentioned, EtOH was used as a co-solvent for $\mathrm{MJ}$ and SA. Figure 4 clearly shows that EtOH reduced the incident of red pigment formation in the calli. In

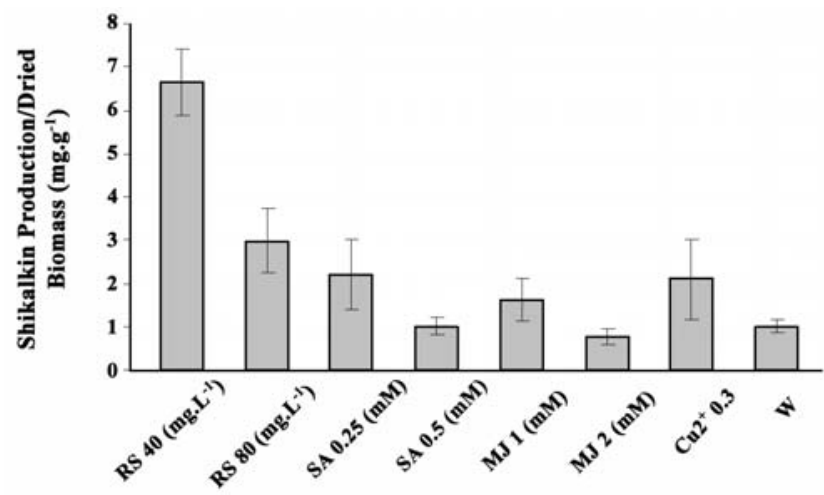

Figure 7. The amount of shikalkin produced by the collar originated calli on White medium (W) and White media containing the effective concentrations of the examined elicitors. RS stands for $R$. solani

other words, EtOH had inhibitory effect on the shikalkin production. Tabata et al. (1974) reported similar observations from the studies on shikalkin production in L. erythrorhizon (20). It seems that the collar-originated callus was more sensitive to EtOH so that no pigment production was observed by this type of callus when the EtOH concentration was raised to $34 \mathrm{mM}$, while the other calli were still producing some shikalkin (Figure 4).

MJ. The role of jasmonate and its derivatives as signaling molecules in response to environmental stresses have been studied (26). According to Yazaki et al. (1997) MJ increases shikalkin production through activating PHB-geranyltransferase (20). This enzyme synthesizes m-geranyl $p$-hydroxy benzoate (Figure 1). Here, the collar originated callus strongly responded to this elicitor. At the optimal concentration of MJ (1 $\mathrm{mM}$ ), the number of collar-calli plates with positive responses was seven times higher than the other calli (Figure 5). Enhancing effect of MJ on biosynthesis of naphthoquinonic metabolites has been reported. In the root culture of Impatiens balsamina, MJ $(0.4 \mathrm{mM})$ increased the production of lawsone and lawsone methylether (naphthoquinonic metabolites) by 6.8 and 11.3 times, respectively (27).

SA. This molecule is recognized as a phytohormone that takes part in higher plants defense responses also known as Systemic Acquired Response (SAR). SA activates signaling pathways that cause secondary metabolite production in plant cultures (28). For instance, application of SA $(1 \mathrm{mM})$ in the culture of Ginkgo biloba resulted in an increase of 3.1 and 6.1 times in the gingkolide A and ginkgolide B production, 
respectively (25). The results illustrated in Figure 5 indicate that SA was able to influence the production capacity of all kinds of A. euchroma calli. However, stronger responses were belonged to the collar originated calli. This observation corroborates the higher biosynthetic ability of the collar originated callus as compared with the other examined calli.

$\boldsymbol{R}$. solani. It is assumed that the elicitation ability of the fungal elicitors is related to the polysaccharide components of their cell walls (29-31). Upon binding of these polysaccharides to a plant cell surface, a cascade of signaling is initiated that leads to expression of genes involved in secondary metabolite production (32). For instance, it has been demonstrated that PAL is activated in the presence of the cell wall fragments of yeast fungal elicitor (33). PAL converts phenylalanine to cinnamic acid, an important precursor in the shikalkin pathway (Figure 1) (10). In this research, the highest amount of pigment production was observed in the presence of $R$. solani ( $40 \mathrm{mg} . \mathrm{L}^{-1}$ ) and the best result was belonged to the collar-originated callus (Figure 5).

Copper ion works as an abiotic elicitor on the shikalkin biosynthesis, however the mechanism of its action has not yet been clearly explained $(34,35)$. The pigment production by the collar originated callus on White media containing effective concentrations of MJ, SA, and $R$. solani revealed that $R$. solani and $\mathrm{Cu}^{2+}$ had similar enhancing effects on the number of the plates with positive responses (Figure 6). In contrast, MJ and SA had about 10\% reducing effects as compared with the results observed for normal White medium, presumably due to the inhibiting effect of the co-solvent (EtOH).

As mentioned, the number of positive responses could be related to the biosynthetic ability of the examined cells, but it had to be quantified. Quantitative analysis of the produced pigment (Figure 7) revealed that the amount of shikalkin produced in the presence of $R$. solani (40 mg.L-1) was about 7 times higher than that produced by normal White medium. While copper ion could increase the pigment production only twice as much as that produced on normal White medium. Considering these results, the following order is concluded for the elicitation effect of the examined elicitors on the shikalkin production by the collar-originated callus of Iranian A. euchroma:

R. solani $>\mathrm{SA} \sim \mathrm{Cu}^{2+}>\mathrm{MJ}$

However, it should be noted that the enhancing effects of SA and MJ were modified by the co-solvent, EtOH.

\section{Acknowledgments}

This work was financially supported by National Institute of Genetic Engineering and Biotechnology of Iran. We appreciate sincere help of our colleagues in Biochemistry and Plant Biotechnology labs.

\section{References}

1. Ordoudi SA, Tsermentseli SK, Nenadis N, Assimopoulou AN, Tsimidou MZ, Papageorgiou VP. Structure-radical scavenging activity relationship of alkannin/shikonin derivatives. Food Chem. 2011;124(1):171-176. DOI: 10.1016/j.foodchem. 2010.06.004

2. Bagheri S, Sanjarian F, Haghbeen K, EbrahimiI MA. Establishment of cell suspention culture from Onosma dasytrichum seed callus culture. Int Res J Appl Basic Sci. 2011;2(10):392-397.

3. Baque MA, Moh SH, Lee EJ, Zhong JJ, Paek KY. Production of biomass and useful compounds from adventitious roots of high-value added medicinal plants using bioreactor. Biotechnol Adv. 2012;30(6):1255-1267. DOI: 10.1016/j. biotechadv.2011.11.004

4. Gupta K, Garg S, Singh J, Kumar M. Enhanced production of napthoquinone metabolite (shikonin) from cell suspension culture of Arnebia sp. and its up-scaling through bioreactor. 3 Biotech. 2014;4(3):263-273. DOI: 10.1007/s13205-0130149-x

5. Chen X, Yang L, Zhang N, Turpin JA, Buckheit RW, Osterling C, et al. Shikonin, a component of Chinese herbal medicine, inhibits chemokine receptor function and suppresses human immunodeficiency virus type 1. Antimicrob Agents Chemoth. 2003;47(9):2810-2816. DOI: 10.1128/AAC.47.9. 2810-2816.2003

6. Dhandapani R, Sarkar AK. Antibacterial activity and UV property of shikonin on silk substrate. JTATM. 2007;5(4):1-7.

7. Fujita Y. Shikonin: production by plant (Lithospermum erythrorhizon) cell cultures. Biotechnol Agric For. 1988;4:225236. DOI: 10.1007/978-3-642-73026-9_11

8. Xiong W, Luo G, Zhou L, Zeng Y, Yang W. In vitro and in vivo antitumor effects of acetylshikonin isolated from Arnebia euchroma (Royle) Johnst (Ruanzicao) cell suspension cultures. Chinese Med. 2009;4(1):14. DOI: 10.1186/ 1749-85464-14

9. Haghbeen K, Pourmolaei S, Mareftjo M, Mousavi A, Akbari Noghabi K, Hosseini Shirazi F, et al. Detailed investigations on the solid cell culture and antimicrobial activities of the Iranian Arnebia euchroma. BioMed Res Int. 2011. DOI: http://dx.doi.org/10.1155/2011/165852

10. Heide L, Nishioka N, Fukui H, Tabata M. Enzymatic regulation of shikonin biosynthesis in Lithospermum erythrorhizon cell cultures. Phytochemistry 1989;28(7):1873-1877. DOI: 10.1016/S0031-9422(00)97877-4

11. Haghbeen K, Mozaffarian V, Ghaffari F, Pourazeezi E, Saraji M, Joupari MD. Lithospermum officinale callus produces shikalkin. Biologia. 2006;61(4):463-467. DOI: 10.2478/s11756-0060077-X

12. Fu X-Q, Lu D-W. Stimulation of shikonin production by combined fungal elicitation and in situ extraction in suspension 
cultures of Arnebia euchroma. Enz Microbiol Technol. 1999;24(5):243-246. DOI: 10.1016/S0141-0229(98)00104-5

13. Fujita Y, Hara Y, Suga C, Morimoto T. Production of shikonin derivatives by cell suspension cultures of Lithospermum erythrorhizon. Plant Cell Rep. 1981;1(2):61-63. DOI: 10.1007/ BF00269273

14. Fujita Y, Maeda Y, Suga C, Morimoto T. Production of shikonin derivatives by cell suspension cultures of Lithospermum erythrorhizon. III. Comparison of shikonin derivatives of cultured cells and Ko-shikon. Plant Cell Rep. 1983;2(4):192-193. DOI: 10.1007/BF00269273

15. Tabata M, Mizukami H, Hiraoka N, Konoshima M. Pigment formation in callus cultures of Lithospermum erythrorhizon. Phytochemistry 1974;13(6):927-932. DOI: 10.1016/S00319422(00)91425-0

16. Namdeo A. Plant cell elicitation for production of secondary metabolites: A review. Pharmacogn Rev. 2007;1(1):69-79.

17. Chung B, Lee YB, Baek MH, Kim JH, Wi S, Kim JS. Effects of low-dose gamma-irradiation on production of shikonin derivatives in callus cultures of Lithospermum erythrorhizon Radiat Phys Chem. 2006;75(9):1018-1023. DOI: 10.1016/j. radphyschem.2005.11.001

18. Lin L, Wu J. Enhancement of shikonin production in singleand two-phase suspension cultures of Lithospermum erythrorhizon cells using low-energy ultrasound. Biotechnol Bioeng. 2002;78(1):81-88. DOI: 10.1002/bit.10180

19. Tani M, Takeda K, Yazaki K, Tabata M. Effects of oligogalacturonides on biosynthesis of shikonin in Lithospermum cell cultures. Phytochemistry 1993;34(5):1285-1290. DOI: 10.1016/ 0031-9422(91)80017-U

20. Yazaki K, Takeda K, Tabata M. Effects of methyl jasmonate on shikonin and dihydroechinofuran production in Lithospermum cell cultures. Plant Cell Physiology. 1997;38(7):776-782. DOI: 10.1093/oxfordjournals.pcp.a029 235

21. Ge F, Wang X, Zhao B, Wang Y. Effects of rare earth elements on the growth of Arnebia euchroma cells and the biosynthesis of shikonin. Plant Growth Regul. 2006;48(3):283-90. DOI: 10.1007/s10725-006-0004-8

22. Blazier SR, Conway KE, Characterization of Rhizoctonia solani isolates associated with patch diseases on turfgrass. Proc Okla Acad Sci. 2004;84: 41-51.

23. Manjkhola S, Dhar U, Joshi M. Organogenesis, embryogenesis, and synthetic seed production in Arnebia euchroma-a critically endangered medicinal plant of the Himalaya. In Vitro Cell Dev Biol Plant. 2005;41(3):244-248. DOI: 10.1079/ IVP2004612

24. Kim BJ, Gibson DM, Shuler ML. Effect of subculture and elicitation on instability of taxol production in Taxus sp. suspension cultures. Biotechnol Prog. 2004;20(6):1666-1673. DOI: $10.1021 / \mathrm{bp} 034274 \mathrm{c}$

25. Kang S-M, Min J-Y, Kim Y-D, Kang Y-M, Park D-J, Jung H$\mathrm{N}$, et al. Effects of methyl jasmonate and salicylic acid on the production of bilobalide and ginkgolides in cell cultures of Ginkgo biloba. In Vitro Cell Dev Biol Plant. 2006;42(1):4449. DOI: 10.1079/IVP2005719

26. Wasternack C. Action of jasmonates in plant stress responses and development-applied aspects. Biotechnol Adv. 2014; 32(1):31-39. DOI: 10.1016/j.biotechadv.2013.09.009
27. Sakunphueak A, Panichayupakaranant P. Increased production of naphthoquinones in Impatiens balsamina root cultures by elicitation with methyl jasmonate. Bioresource Technol. 2010;101(22):8777-8783. DOI: 10.1016/j.biortech.2010.06. 067

28. Derksen H, Rampitsch C, Daayf F. Signaling cross-talk in plant disease resistance. Plant Sci. 2013;207:79-87. DOI: 10.1016/j.plantsci.2013.03.004

29. Shibuya N, Minami E. Oligosaccharide signalling for defence responses in plant. Physiol Mol Plant Pathol. 2001;59(5):223233. DOI: 10.1006/pmpp.2001.0364

30. Orbán N, Boldizsár I, Szűcs Z, Dános B. Influence of different elicitors on the synthesis of anthraquinone derivatives in Rubia tinctorum L. cell suspension cultures. Dyes Pigments. 2008;77(1):249-257. DOI: 10.1016/j.dyepig.2007. 03.015

31. Hadwiger LA. Multiple effects of chitosan on plant systems: Solid science or hype. Plant Sci. 2013;208:42-49. DOI: 10.1016/j.plantsci.2013.03.007

32. Wu S, Shan L, He P. Microbial signature-triggered plant defense responses and early signaling mechanisms. Plant Sci. 2014;228:118-126. DOI: 10.1016/j.plantsci.2014.03.001

33. Sullivan M. Phenylalanine ammonia lyase genes in red clover: expression in whole plants and in response to yeast fungal elicitor. Biologia Plantarum. 2009;53(2):301-306. DOI: $10.1007 / \mathrm{s} 10535-009-0054-7$

34. Poschenrieder C, Tolrà R, Barceló J. Can metals defend plants against biotic stress? Trends Plant Sci. 2006;11(6):288-295. DOI: 10.1016/j.tplants.2006.04.007

35. Smékalová V, Doskočilová A, Komis G, Šamaj J. Crosstalk between secondary messengers, hormones and MAPK modules during abiotic stress signalling in plants. Biotechnol Adv. 2014;32(1):2-11. DOI: 10.1016/j.biotechadv.2013.07.009 